\title{
Recognition of Bimolecular Logic Operation Pattern Based on a Solid-State Nanopore
}

\author{
Han Yan ${ }^{1,+}$, Zhen Zhang ${ }^{1,+}$, Ting Weng ${ }^{2}$, Libo Zhu ${ }^{1}$, Pang Zhang ${ }^{2}$, Deqiang Wang ${ }^{2}$ and Quanjun Liu ${ }^{1, *}$ \\ 1 State Key Laboratory of Bioelectronics, School of Biological Science and Medical Engineering, Southeast \\ University, No. 2, Sipailou, Nanjing 210096, China; 230209118@seu.edu.cn (H.Y.); \\ 220181842@seu.edu.cn (Z.Z.); 230169449@seu.edu.cn (L.Z.) \\ 2 Chongqing Institute of Green and Intelligent Technology, Chinese Academy of Sciences, Chongqing 400714, \\ China; wengting@cigit.ac.cn (T.W.); zhangpang@cigit.ac.cn (P.Z.); dqwang@cigit.ac.cn (D.W.) \\ * Correspondence: lqj@seu.edu.cn \\ + These authors contributed equally to this work.
}

check for

updates

Citation: Yan, H.; Zhang, Z.; Weng, T.; Zhu, L.; Zhang, P.; Wang, D.; Liu, Q. Recognition of Bimolecular Logic Operation Pattern Based on a SolidState Nanopore. Sensors 2021, 21, 33. https://dx.doi.org/10.3390/s21010033

Received: 5 December 2020

Accepted: 21 December 2020

Published: 23 December 2020

Publisher's Note: MDPI stays neutral with regard to jurisdictional claims in published maps and institutional affiliations.

Copyright: () 2020 by the authors. Licensee MDPI, Basel, Switzerland. This article is an open access article distributed under the terms and conditions of the Creative Commons Attribution (CC BY) license (https: / / creativecommons.org/ licenses/by/4.0/).

\begin{abstract}
Nanopores have a unique advantage for detecting biomolecules in a label-free fashion, such as DNA that can be synthesized into specific structures to perform computations. This method has been considered for the detection of diseased molecules. Here, we propose a novel marker molecule detection method based on DNA logic gate by deciphering a variable DNA tetrahedron structure using a nanopore. We designed two types of probes containing a tetrahedron and a singlestrand DNA tail which paired with different parts of the target molecule. In the presence of the target, the two probes formed a double tetrahedron structure. As translocation of the single and the double tetrahedron structures under bias voltage produced different blockage signals, the events could be assigned into four different operations, i.e., $(0,0),(0,1),(1,0),(1,1)$, according to the predefined structure by logic gate. The pattern signal produced by the AND operation is obviously different from the signal of the other three operations. This pattern recognition method has been differentiated from simple detection methods based on DNA self-assembly and nanopore technologies.
\end{abstract}

Keywords: nanopore; DNA logic gate; DNA tetrahedron; probe; AND operation

\section{Introduction}

Since the advent of DNA computation, it has been receiving more and more attention due to its good biocompatibility. In a traditional electronic computer, a microprocessor uses basic logic gates (AND, OR, NOT, etc.) to construct an electronic circuit capable of performing Boolean mathematical logic. This is crucial for modern computers, and these computer concepts have a similar understanding in biology. In fact, a human body is likely a complex biological computer, which performs a lot of logical operations. A variety of materials have been used to construct logic gates such as enzymes, DNA, RNA, and other biological molecules [1-6].

Recently, DNA molecular hybridization processes and ribozyme-based logic operations have been widely considered to be logic gates. The design of a DNA logic gate mainly depends on the properties of DNA molecules, such as base pairing [7,8], single strand replacement [9], DNAzyme cleavage [10,11], nucleic acid aptamer binding, i-motif structure interconversion, and DNA tweezers [12-14]. In the design of DNA computing, biomolecules contain biological information, such as molecular spatial conformation, enzyme activity, catalytic properties, and recognition sites of enzymes, which can be converted into logic operations [15-20]. Over the past few years, this method has been often applied to detect biomarkers of various diseases. However, most of the decoding of the output terminal is still realized by PCR fluorescence amplification or gel electrophoresis [21,22], which are time-consuming.

In recent years, nanopores have been broadly developed for detecting and identifying biomolecules. In a typical setup, an external voltage drives a biomolecule through a 
nanometer-size pore in a thin supporting membrane, causing a characteristic temporary change in the translocation ionic current. Nanopore technology can be applied to assay the spatial structure [23-25], dynamic changes [25-29], and biochemical characteristics [30,31]. It is not necessary to carry out chemical modification, surface adsorption, and calibration object insertion, which may affect the activity of the sample. Due to its advantages of rapid reading and label-free detection [32-35], the nanopore platform has been developed into a powerful tool for detecting biomolecules. It has been applied to detect and analyze the types and structures of biomolecules, such as polymer morphology, morphology and sequencing of DNA and RNA [36], virus and antibody-virus interactions [37], morphology of amino acid [38], peptides and proteins [39-46], ribosomes, and chemical bond formation [47-49]. In addition, some synthetic nanostructures with special configurations have also been detected by nanopores, such as DNA tetrahedrons and other DNA origami structures [50-53]. In view of this, Ryuji Kawano et al. used biological nanopores to design a DNA logic gate for the detection of lung cancer markers [54]. Ulrich F. Keyser designed a DNA hard drive using glass nanopores, for storage, calculation, and reading of data in a variable DNA three-dimensional structure [55]. Inspired by these works, we have designed a kind of DNA logic gate based on a solid-state nanopore platform and DNA tetrahedrons. DNA tetrahedrons are highly rigid and well-defined structures with atomic precision and versatile functionality, and they provide scaffolds for anchoring of a variety of biomolecular probes (DNA, aptamers, peptides, and proteins) for biosensing. Significantly, this DNA nanostructure-based biosensing platform greatly increases target accessibility and improves the sensitivity for various types of molecular targets (DNA, RNA, proteins, and small molecules) by several orders of magnitude. In addition, the DNA tetrahedron also has the characteristics of a stable structure and uniform size. In recent years, several DNA-based sensors have been published with high sensitivity towards biomarker detection [56-58]. In order to realize the decoding application of a solid-state nanopore, it is necessary to obtain signals with a higher signal-to-noise ratio. To this end, we have constructed a logic operator assisted with a tetrahedral structure which can provide an improved signal-to-noise ratio and temporal resolution, due to its unique spatial structure and carried charges, as the DNA tetrahedron has been applied to build various biosensors [59-66].

In this paper, we designed a DNA logic gate operation based on nanopore measurement and pattern recognition of DNA computing technology. We attempted to construct an AND operation using a lung cancer marker recognition locus (miR-21), which included four operation patterns, i.e., $(0,0),(0,1),(1,0),(1,1)$. The lung cancer marker recognition locus used in our experiments was converted into corresponding DNA. According to our experimental design, when two tetrahedron probes were presented at the same time, they formed a double tetrahedron structure with the marker molecule and resulted in a long blocking signal, when the structure translocated through the nanopore, as shown in the schematic diagram of Figure 1. By the analysis of duration and amplitude of the signal, the signal of $(1,1)$ can be distinguished from the other three patterns $((0,0),(0,1),(1,0))$. 


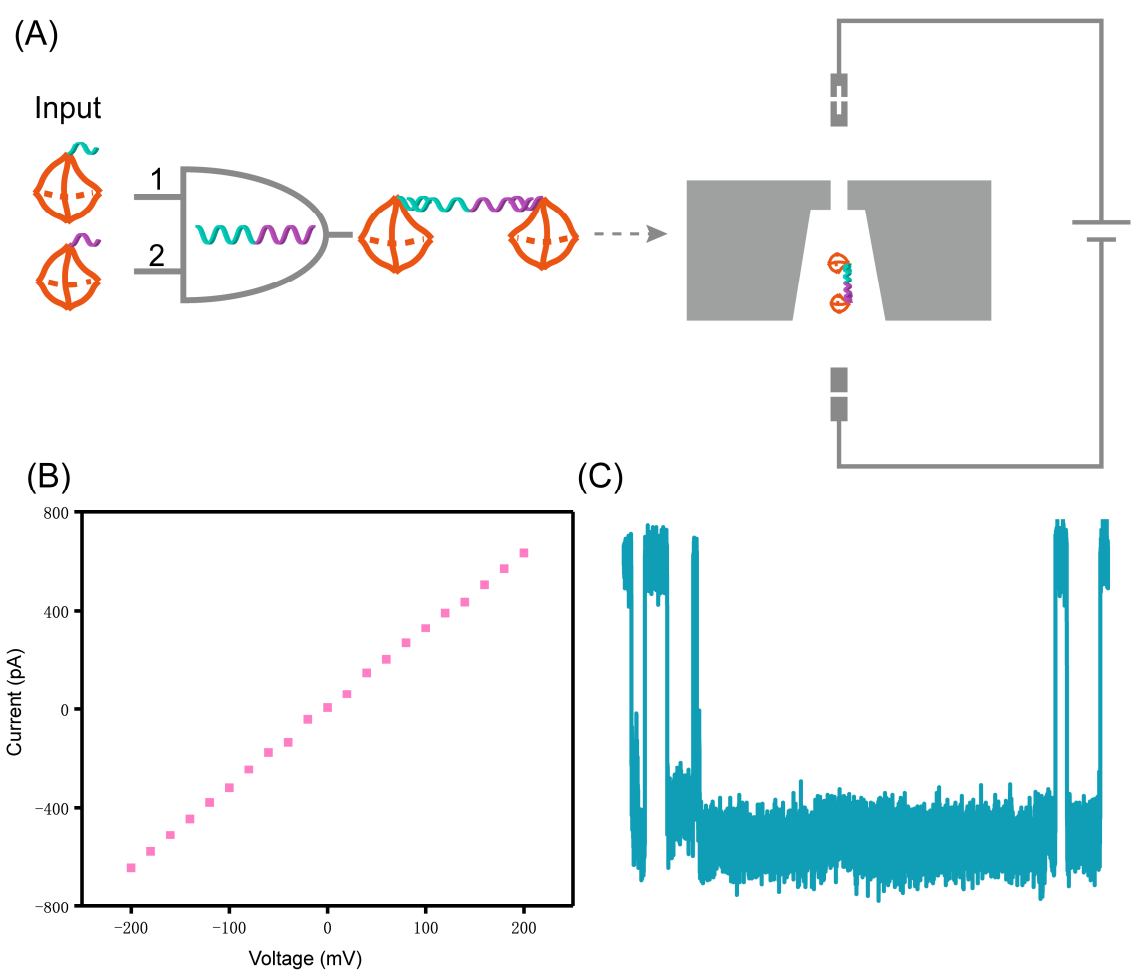

Figure 1. (A) Schematic illustration of the AND gate for marker molecules of lung cancer. When Probe 1 and Probe 2 are provided as inputs at the same time, they form a double tetrahedral structure with the marker molecules, causing a long blockage when translocated through the solid-state nanopore under an external voltage; (B) I-V characterization curve of the SiNx nanopore with a diameter about $3.5 \mathrm{~nm}$ in the range $\pm 200 \mathrm{mV}$; (C) The signals after the AND operation.

\section{Materials and Methods}

\subsection{Chemical and Instrument}

All aqueous solutions were prepared using ultrapure water from a Milli-Q water purification system (Millipore Corporation, Billerica, MA, USA) and were filtered with $0.22 \mu \mathrm{m}$ needle filter unit. Lithium chloride $(\mathrm{LiCl})$ was purchased from Sigma. TE buffer $(\mathrm{pH}=8)$ was composed of $10 \mathrm{mM}$ Tris and $1 \mathrm{mM}$ EDTA (ethylenediaminetetraacetic acid), of which Tris and EDTA were provided by Sigma. The electrolyte used in the experiment was a mixture of $1 \mathrm{M} \mathrm{LiCl}, 10 \mathrm{mM}$ Tris and $1 \mathrm{mM}$ EDTA. TM (Tris $\left.\mathrm{MgCl}_{2}\right)$ buffer $(20 \mathrm{mM}$ Tris, $50 \mathrm{mM} \mathrm{MgCl}_{2}, \mathrm{pH}=8$ ) was used in the synthesis of the tetrahedron probe. All the prepared solutions were stored in the refrigerator at $-4{ }^{\circ} \mathrm{C}$. The silicon nitride chips used in the experiments were purchased from Norcada. During the experiments, the signals were acquired through the patch clamp system (Axon Axopatch 200B, Molecular Devices, San Jose, CA, USA).

\subsection{Nanopore Fabrication and Measurement}

The size of nanopore chips are $3 \times 3 \mathrm{~mm}^{2}$, showing a sandwich structure, in which the thickness of the upper and lower layers of silicon nitride is $15 \mathrm{~nm}$. Firstly, the nanopore chip was mounted in the flow cell (Figure S1), and two Viton O-rings were used to seal the chambers to ensure that the nanopore was the only channel connecting the two chambers (cis and trans chamber). Then, the chamber was washed with ultrapure water and absolute ethanol three times alternately to increase the wettability of the nanopore sheet to avoid the generation of air bubbles during drilling and experiments. Finally, the two chambers were filled with electrolyte, and a $3.5 \mathrm{~nm}$ nanopore was fabricated on the $\mathrm{Si}_{3} \mathrm{~N}_{4}$ freestanding membrane by dielectric breakdown [67]. After the nanopore was fabricated, it was also washed three times with ultrapure water and absolute ethanol alternately to ensure that the 
nanopore was clean. The open-pore current was tested by I-V cures before the experiment to calculate the diameter of the nanopore. This result is shown in Figure 1B.

\subsection{Synthesis of Tetrahedron Probes}

Each of the single stranded and the tetrahedron probes was dissolved in TM buffer, and then mixed in equal volume. The mixture was heated to $95{ }^{\circ} \mathrm{C}$ for $10 \mathrm{~min}$ in the water bath, and then quickly cooled to $4{ }^{\circ} \mathrm{C}$. The prepared sample was stored in the refrigerator at $-20^{\circ} \mathrm{C}$. For the logic operations, input DNAs (sequences listed in Table S1) were added in the mixture, and then incubated for $30 \mathrm{~min}$ to operate the logic gates under room temperature. In our experiment, each edge length of the synthesized DNA tetrahedral probe was $2.4 \mathrm{~nm}$. The four oligonucleotide strands used to synthesize the tetrahedron probe and the DNA strands used in the experiment are displayed in the supporting information (Table S1). Gel electropherograms of different DNA configurations are displayed in the Supporting Information (Figure S2). The synthesis and characterization of tetrahedrons can be referred to in our previous work in detail [52].

\section{Results and Discussion}

The nanopore can be used to detect the output biomolecules of DNA logic operations quickly in a label-free fashion. Before the logic operation experiments, we detected the two tetrahedron probes. Figure S3 shows the current traces from two tetrahedron probes $\left(\mathrm{T}_{1}\right.$ and $\left.\mathrm{T}_{2}\right)$. The $\mathrm{T}_{1}$ tetrahedral probe is composed of $\mathrm{A} 7, \mathrm{~B} 7-\mathrm{C} 1, \mathrm{C} 7$, and $\mathrm{D} 7$, while the $\mathrm{T}_{2}$ tetrahedral probe is composed of A7, B7-C2, C7, and D7. The analysis of amplitude and duration are shown in the Supporting Information (Figure S4). As shown in Figure S4, the average translocation amplitude and duration of T1 and T2 are $186.34 \pm 0.301 \mathrm{pA}$, $6.35 \pm 0.058 \mathrm{~ms}$, and $186.82 \pm 0.306 \mathrm{pA}, 8.96 \pm 0.140 \mathrm{~ms}$, respectively. The results indicate that there is no significant difference in the amplitude and duration of the two probes, due to their similar structure. However, as compared with single-strand DNA (105.32 $\pm 0.287 \mathrm{pA}$ and $0.15 \pm 0.002 \mathrm{~ms}$ ), the three-dimensional (3D) structure of DNA probes greatly increases the duration and amplitude. The main reason for this phenomenon is that the $3 \mathrm{D}$ spatial structure of the tetrahedral probe intensifies the interaction with the nanopore wall when passing through the nanopore. Figure S5 presents the duration and amplitude of the tetrahedron probes $\left(\mathrm{T}_{1}\right.$ and $\left.\mathrm{T}_{2}\right)$ and corresponding complex of DNA-tetrahedron probe (Figure $2 b(0,1)$ and Figure $2 c(1,0)$ ). As a result of the analysis, the amplitude and duration in the logical operation pattern of $(0,1)$ and $(1,0)$ can be clearly distinguished from T1 and T2. The tetrahedral probes with a longer chain length after the logic gate operation caused a larger amplitude and duration when translocating through the nanopore. Furthermore, we detected four operations, i.e., $(0,0),(0,1),(1,0),(1,1)$ by the solid-state nanopore. Unless otherwise specified, the electrolyte used in the experiments is $1 \mathrm{M} \mathrm{LiCl}$, the applied voltage is $100 \mathrm{mV}$, and the concentration of the detected analytes is $10 \mathrm{nM}$. Figure 2 shows the current traces for four operations. For $(0,0)$ it represents the DNA fragment (Table S1) corresponding to the lung cancer marker (miR-21), which only causes spikelike and short-lived translocation signals (Figure 2a). In the case of $(0,1)$ and $(1,0)$, as demonstrated in Figure 2b,c, they represent a complex of DNA and different molecular probes. As compared with the signals produced by single-stranded DNA, the complex of a single tetrahedral probe and the marker has a 3D spatial structure. When it translocates through the nanopore under the action of an external voltage, it interacts more strongly with the wall of the nanopore, resulting in a significant increase in translocation time (Figure 2b,c). For AND logic $(1,1)$, two input tetrahedron probes (Probe 1, and Probe 2) are designed to combine into the double tetrahedron structures (Figure 2d). As a result, we can observe the long-lived translocation blockage signals (output $=1$ ) only when both inputs are present (input $=(1,1)$ ); otherwise (input $=(0,0),(1,0)$, or $(0,1))$ the duration level is low (output $=0$ ). It can be found intuitively from the recorded current curves. From the current traces, we can also intuitively observe that the proportion of long-lived translocation signals has increased significantly after the AND operation. 
(a)

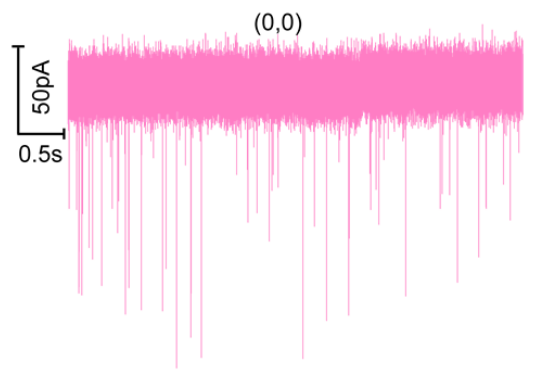

wr

(c)

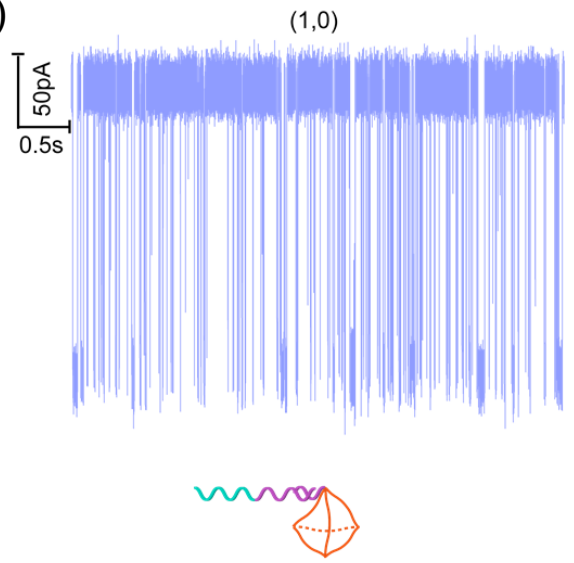

$(0,1)$
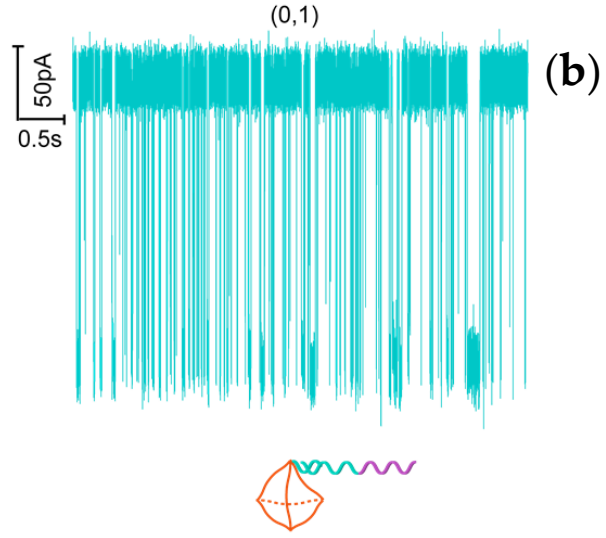

$(1,1)$

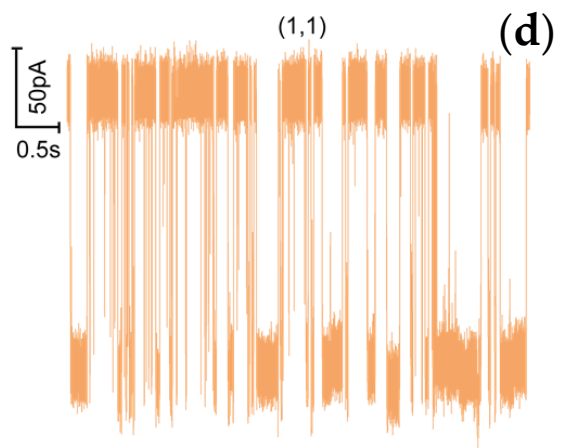

(d)

Figure 2. (a-d) Continuous current traces for different DNA logic operations $(0,0),(0,1),(1,0),(1,1)$ translocation through a $3.5 \mathrm{~nm}$ diameter solid-state nanopore under $100 \mathrm{mV}$ voltage in $1 \mathrm{M} \mathrm{LiCl}$. The concentrations of tetrahedron Probe 1 and Probe 2 were $10 \mathrm{nM}$, respectively. The molar ratios of Probe 1/Probe 2/DNA(miR-21) are 0:0:1 in $(0,0), 0: 1: 1$ in $(0,1), 1: 0: 1$ in $(1,0)$, and 1:1:1 in $(1,1)$.

Furthermore, the data from four DNA logic operations are analyzed. The mean amplitude of $(0,0),(0,1),(1,0),(1,1)$ was $106.17 \pm 0.95 \mathrm{pA}, 205.82 \pm 0.78 \mathrm{pA}, 206.79 \pm 0.99 \mathrm{pA}$, and $215.28 \pm 0.55 \mathrm{pA}$, respectively, as shown in Figure 3. According to the results of the analysis, the presence of the tetrahedral probe increases the translocation amplitude and also increases the signal-to-noise ratio. It can be found that the amplitude of $(1,1)$ is slightly different from the amplitude of $(0,1)$ and $(1,0)$, however the amplitude of $(0,1)$ is almost the same as that of $(1,0)$. It is reasonable that the configuration is almost the same for Probe 1 and Probe 2 (T1 tetrahedral probe is composed of A7, B7-C1, C7, and D7, while T2 tetrahedral probe is composed of $\mathrm{A} 7, \mathrm{~B} 7-\mathrm{C} 2, \mathrm{C} 7$, and D7), the same tetrahedron with a single strand that is partially complementary to the DNA fragment (miR-21). The slight difference in amplitude between $(0,1),(1,0)$ and $(1,1)$ might be caused by the almost uniform lateral occupation ratio of the molecular translocation through the nanopore. It means that the double tetrahedron structure has no advantage over the single tetrahedron in increasing the signal amplitude. Therefore, based on the analysis of amplitude alone, we cannot distinguish the three patterns of logic operation $((0,1),(1,0)$, and $(1,1))$. 
(a)

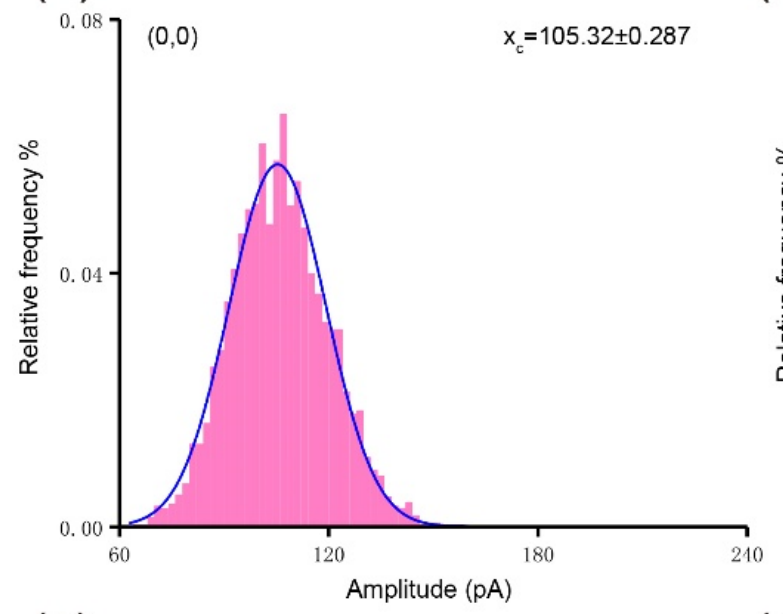

(c) (b)

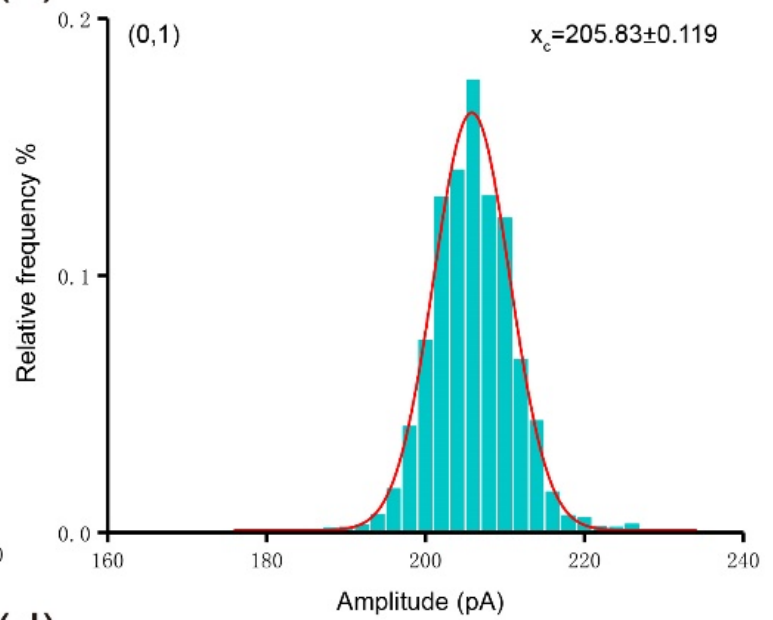

(d)

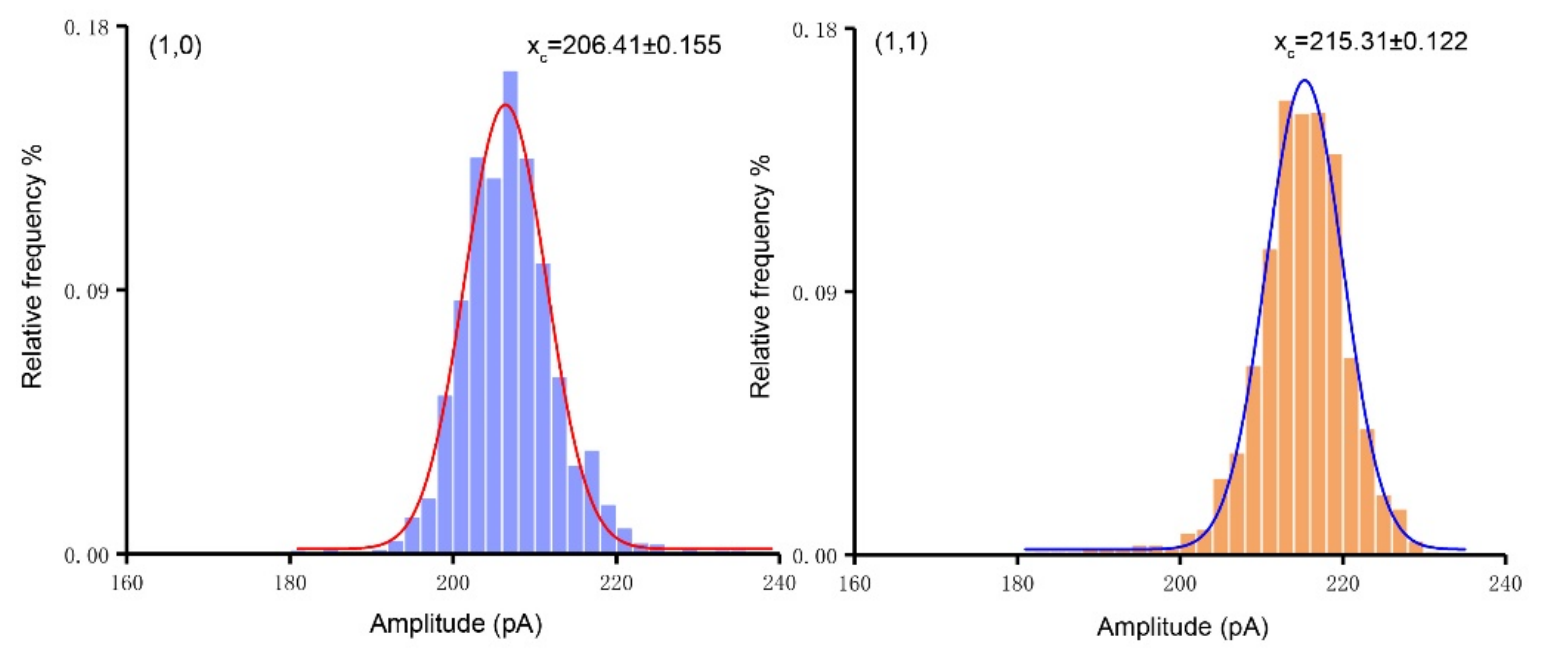

Figure 3. (a-d) Histograms of the amplitude for each AND operation pattern. Solid lines are Gaussian fitted curves for each group of data.

Analogous to the analysis of amplitude, we also analyzed the translocation time of the four operation patterns, and the histograms of dwell time are shown in Figure 4. The mean duration for $(0,0),(0,1),(1,0),(1,1)$ is $0.16 \pm 0.0004 \mathrm{~ms}, 13.49 \pm 0.107 \mathrm{~ms}, 13.85 \pm 0.051 \mathrm{~ms}$, and $114.04 \pm 1.379 \mathrm{~ms}$, respectively. We can observe that the translocations of $(0,1)$ and $(1,0)$ show a significant difference from the translocation time of $(1,1)$. The increase in duration by an order of magnitude from $(0,0)$ to $(0,1) /(1,0)$, and then to $(1,1)$ is attributed to two factors. On the one hand, the spatial conformation changed after the probe was combined with the DNA marker. On the other hand, the changed molecular conformation exacerbates the interaction between the molecules with the nanopore wall during translocation. Therefore, as compared with the complex of single tetrahedral probe, although the double tetrahedron failed to cause a larger current blockage, the strong interaction with the nanopore wall during translocation obviously improved its translocation time. Similarly, the translocation time of the complex of the single tetrahedral probe and the marker is also significantly higher than the duration of the individual DNA fragment marker. Therefore, we can distinguish $(0,0),(0,1) /(1,0)$, and $(1,1)$ of operation patterns according to the translocation time. Further normalization of the amplitude reveals a conspicuous difference between $(0,0)$ and $(1,1)$. We observe that the deep current blockage exceeds $70 \%$ of the threshold level, as shown in Figure 5D. In addition, the scatter plot based on duration and 
amplitude is shown in Figure 5C. These data graphs help us to improve our experiments and to make our experimental results more convincing.
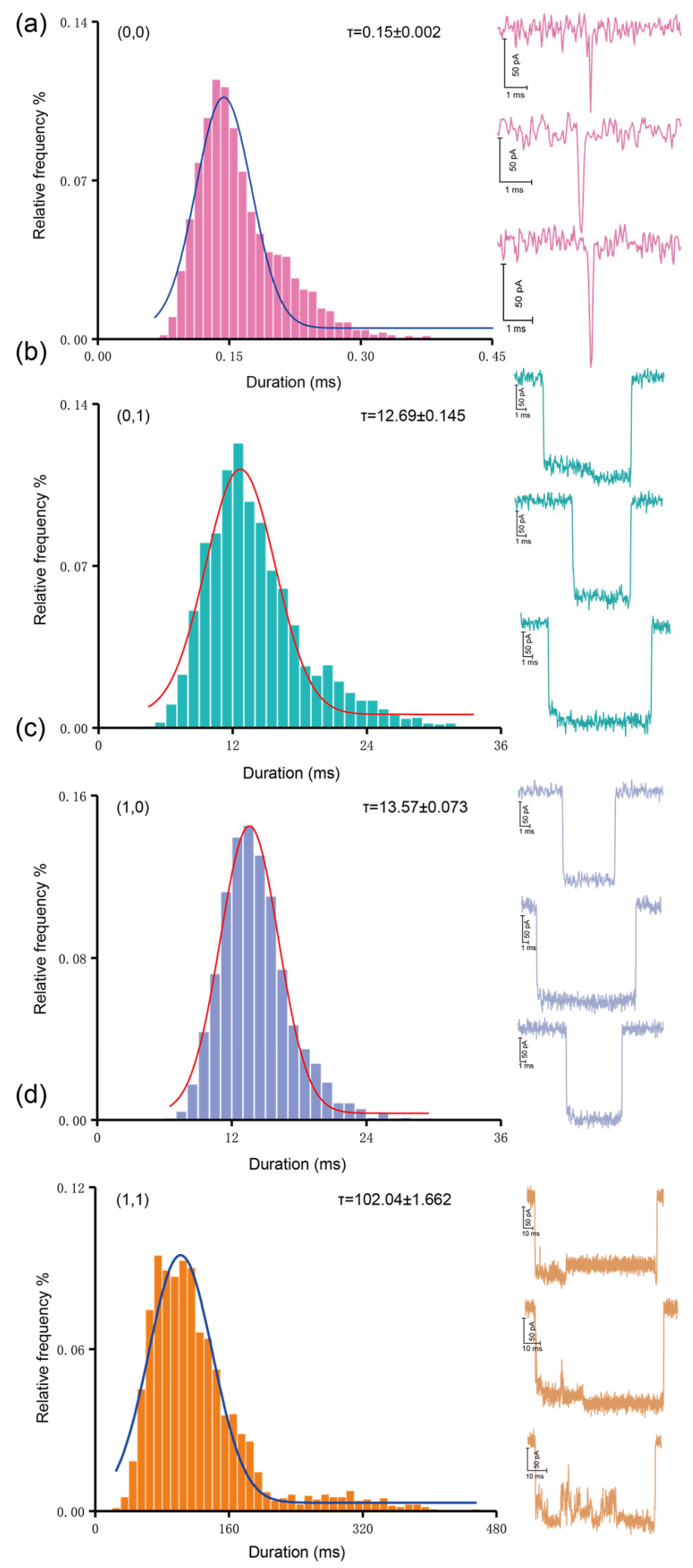

Figure 4. (a-d) Histograms of the mean of duration for each AND operation pattern. Solid lines are Gaussian fitted curves for each group of data. All data is obtained through a nanopore with a $3.5 \mathrm{~nm}$ diameter nanopore under a voltage of $100 \mathrm{mV}$. 
(A)
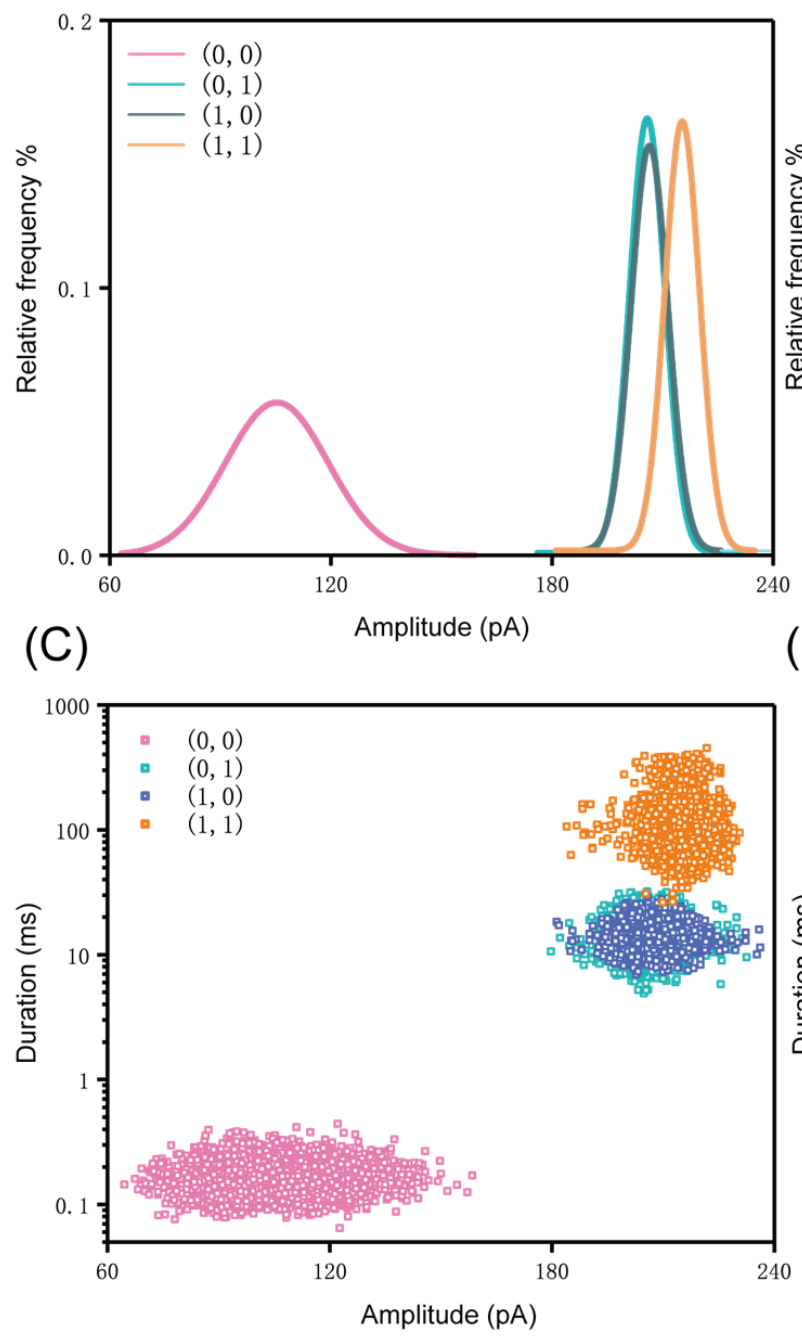

(B)
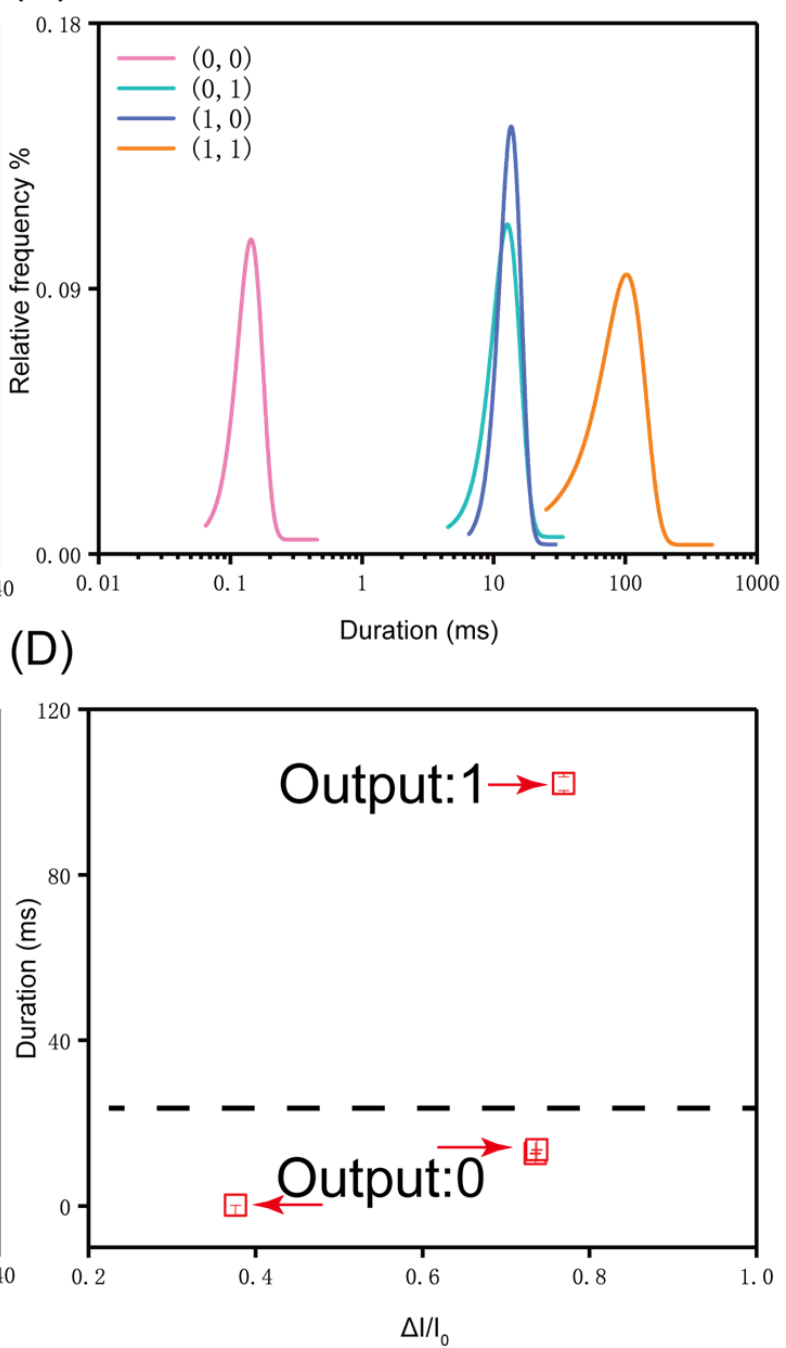

Figure 5. (A,B) The comparison curve of amplitude and translocation time, the curves are the Gaussian fitting curve obtained from each group of histograms; (C) Represents the scatter plot of duration vs. amplitude for four operation patterns under a voltage of $100 \mathrm{mV}$; (D) The dot plot of average duration and normalized amplitude. The figure shows the results of two logical operations (0 and 1$)$.

Finally, we uniformly compare the amplitude and duration obtained from the four groups of logical operations; the results are shown in Figure 5A,B. As presented in Figure 5C, we plotted a scatter plot of four sets of data. Subsequently, we analyzed the average amplitude and mean of duration obtained from each group of DNA logic operations. The specific analysis is shown in Figure 5D. In this analysis, we normalized the average amplitude of each group of data, which better reflected the difference among the four DNA logic operations. According to the analysis of duration and amplitude, the signals of the AND operation $(1,1)$ can be clearly distinguished from other three operations $((0,0),(0,1)$, $(1,0))$, as shown in Figure 5D. This means that when we input two tetrahedral probes at the same time, they can perform the AND operation with the substrate molecule successfully. Combined with the Figures S2 and S3, the logic operation patterns of $(0,1)$ and $(1,0)$ are also successfully executed.

\section{Conclusions}

We designed a DNA logic gate (AND gate) based on a tetrahedron probe, including four operation patterns of $(0,0),(0,1),(1,0),(1,1)$. Different operation patterns correspond to different blocking signals under the measurements of a solid-state nanopore. The double 
tetrahedron structure corresponding to operation mode $(1,1)$ caused a long blocking signal when it passed through a nanopore. Combining the translocation time and amplitude of different types of signals, the signals of $(1,1)$ can be distinguished from the other three operation patterns, which has been confirmed by our analysis of the signals from different operation patterns. In addition, this strategy can be integrated into molecular machines to form a nanopore-based biochemical molecular machine. In the future, due to the ability of parallel computing, DNA computing could solve mathematical problems and could also be applied to study physical and chemical processes of various biomolecules. Therefore, the nanopore platform will become an important tool for DNA computations due to its advantages in the detection process.

Supplementary Materials: The following are available online at https:/ /www.mdpi.com/1424-822 0/21/1/33/s1, Figure S1: Structure diagram of flow cell; Figure S2: Gel electrophoresis of molecules with different structure; Figure S3: Current trace of the tetrahedral probes; Figure S4: The histogram for different tetrahedral probes. Figure S5: Gaussian fitting curves of the histogram for two kinds of tetrahedral probes and DNA logic operation patterns and the scatter plot of amplitude versus duration; Table S1: DNA sequence used in the experiment.

Author Contributions: The idea was inspired by Q.L. and D.W.; H.Y. and T.W. designed the experimental plan; H.Y., Z.Z. and P.Z. performed the experiment and analyzed the experimental data; H.Y., L.Z., and T.W. wrote this article together. All authors have read and agreed to the published version of the manuscript.

Funding: This research was supported by the National Natural Science Foundation of China (61827814 and 31872726), the National Key R\&D Program of Chain (2017YFC0906503 and 2016YFA0501600), and West Light Foundation of CAS attributed to Weng Ting.

Institutional Review Board Statement: The study did not involve ethical research.

Informed Consent Statement: The study did not involve ethical research.

Data Availability Statement: The data presented in this study are available on request from the corresponding author. The data are not publicly available because the research is still ongoing.

Acknowledgments: Thanks for the guidance given by Huma Bhatti during the writing process.

Conflicts of Interest: There are no conflicts declare.

\section{References}

1. Zhou, J.; Arugula, M.A.; Halamek, J.; Pita, M.; Katz, E. Enzyme-Based NAND and NOR logic gates with modular design. J. Phys. Chem. B 2009, 113, 16065-16070. [CrossRef]

2. De Silva, P.A.; Gunaratne, N.H.Q.; McCoy, C.P. A molecular photoionic and gate based on fluorescent signalling. Nat. Cell Biol. 1993, 364, 42-44. [CrossRef]

3. Privman, M.; Tam, T.K.; Pita, M.; Katz, E. Switchable electrode controlled by enzyme logic network system: approaching physiologically regulated bioelectronics. J. Am. Chem. Soc. 2009, 131, 1314-1321. [CrossRef]

4. Amir, L.; Tam, T.K.; Pita, M.; Meijler, M.M.; Alfonta, L.; Katz, E. Biofuel cell controlled by enzyme logic systems. J. Am. Chem. Soc. 2009, 131, 826-832. [CrossRef]

5. Szaciłowski, K.; Macyk, W.; Stochel, G. Light-Driven or and Xor programmable chemical logic gates. J. Am. Chem. Soc. 2006, 128, 4550-4551. [CrossRef] [PubMed]

6. Weizmann, Y.; Elnathan, R.; Lioubashevski, O.; Willner, I. Endonuclease-Based logic gates and sensors using magnetic forceamplified readout of DNA scission on cantilevers. J. Am. Chem. Soc. 2005, 127, 12666-12672. [CrossRef] [PubMed]

7. Ogasawara, S.; Ami, T.; Fujimoto, K. Autonomous DNA computing machine based on photochemical gate transition. J. Am. Chem. Soc. 2008, 130, 10050-10051. [CrossRef] [PubMed]

8. Ogasawara, S.; Kyoi, Y.; Fujimoto, K. Nonenzymatic parallel DNA logic circuits. ChemBioChem 2007, 8, 1520-1525. [CrossRef] [PubMed]

9. Elbaz, J.; Wang, Z.G.; Orbach, R.; Willner, I. Ph-Stimulated concurrent mechanical activation of two DNA “Tweezers". A “SetReset" Logic Gate System. Nano Lett. 2009, 9, 4510-4514. [CrossRef] [PubMed]

10. Saghatelian, A.; Voelcker, N.H.; Guckian, K.M.; Lin, A.V.S.-Y.; Ghadiri, M.R. DNA-Based photonic logic gates: And, Nand, and Inhibit. J. Am. Chem. Soc. 2003, 125, 346-347. [CrossRef] [PubMed]

11. Voelcker, N.H.; Guckian, K.M.; Saghatelian, A.; Ghadiri, M.R. Sequence-Addressable DNA logic. Small 2008, 4, 427-431. [CrossRef] [PubMed] 
12. Stojanovic, M.N.; Mitchell, T.E.; Stefanovic, D. Deoxyribozyme-Based logic gates. J. Am. Chem. Soc. 2002, $124,3555-3561$. [CrossRef] [PubMed]

13. Fahlman, R.P.; Hsing, M.; Sporer-Tuhten, C.S.; Sen, D. Duplex pinching: A structural switch suitable for contractile DNA nanoconstructions. Nano Lett. 2003, 3, 1073-1078. [CrossRef]

14. Benenson, Y.; Paz-Elizur, T.; Adar, R.; Keinan, E.; Livneh, Z.; Shapiro, E. Programmable and autonomous computing machine made of biomolecules. Nat. Cell Biol. 2001, 414, 430-434. [CrossRef]

15. Jian, Z.; Zhang, Z.Z.; Shi, Y.Y.; Li, X.X.; He, L. Linearly programmed DNA-Based molecular computer operated on magnetic particle surface in test-tube. Chin. Sci. Bull. 2004, 49, 17-22.

16. Harding, B.I.; Pollak, N.M.; Stefanovic, D.; Macdonald, J. Repeated reuse of Deoxyribozyme-Based logic gates. Nano Lett. 2019, 19, 7655-7661. [CrossRef]

17. Jiao, K.; Zhu, B.; Guo, L.; Zhou, H.; Wang, F.; Zhang, X.; Shi, J.; Li, Q.; Wang, L.; Li, J.; et al. Programming switchable transcription of topologically constrained DNA. J. Am. Chem. Soc. 2020, 142, 10739-10746. [CrossRef]

18. Nakama, T.; Takezawa, Y.; Sasaki, D.; Shionoya, M. Allosteric regulation of DNAzyme activities through intrastrand transformation induced by $\mathrm{Cu}(\mathrm{II})$-mediated artificial base pairing. J. Am. Chem. Soc. 2020, 142, 10153-10162. [CrossRef]

19. Barnoy, E.A.; Popovtzer, R.; Fixler, D. Fluorescence for biological logic gates. J. Biophotonics 2020, 13, e202000158. [CrossRef]

20. Goldsworthy, V.; LaForce, G.; Abels, S.; Khisamutdinov, E.F. Fluorogenic RNA Aptamers: A nano-platform for fabrication of simple and combinatorial logic gates. Nanomaterials 2018, 8, 984. [CrossRef]

21. Matsuura, S.; Ono, H.; Kawasaki, S.; Kuang, Y.; Fujita, Y.; Saito, H. Synthetic RNA-based logic computation in mammalian cells. Nat. Commun. 2018, 9, 4847. [CrossRef] [PubMed]

22. Hu, Z.; Jian, J.; Hua, Y.; Yang, D.; Gao, Y.; You, J.; Wang, Z.; Chang, Y.; Yuan, K.; Bao, Z.; et al. DNA colorimetric logic gate in microfluidic chip based on unmodified gold nanoparticles and molecular recognition. Sens. Actuators B Chem. 2018, 273, 559-565. [CrossRef]

23. Cao, C.; Ying, Y.-L.; Hu, Z.-L.; Liao, D.-F.; Tian, H.; Long, Y.-T. Discrimination of oligonucleotides of different lengths with a wild-type aerolysin nanopore. Nat. Nanotechnol. 2016, 11, 713-718. [CrossRef]

24. Bandarkar, P.; Yang, H.; Henley, R.; Wanunu, M.; Whitford, P.C. How nanopore translocation experiments can measure RNA unfolding. Biophys. J. 2020, 118, 1612-1620. [CrossRef] [PubMed]

25. Li, Q.; Ying, Y.-L.; Liu, S.-C.; Hu, Y.-X.; Long, Y.-T. Measuring temperature effects on nanobubble nucleation via a solid-state nanopore. Analyst 2020, 145, 2510-2514. [CrossRef]

26. Ying, Y.-L.; Yu, R.-J.; Hu, Y.-X.; Gao, R.; Long, Y.-T. Single antibody-antigen interactions monitored via transient ionic current recording using nanopore sensors. Chem. Commun. 2017, 53, 8620-8623. [CrossRef]

27. Li, M.-Y.; Wang, Y.-Q.; Ying, Y.-L.; Long, Y.-T. Revealing the transient conformations of a single flavin adenine dinucleotide using an aerolysin nanopore. Chem. Sci. 2019, 10, 10400-10404. [CrossRef]

28. Yu, H.; Li, Z.; Tao, Y.; Sha, J.; Chen, Y. Thermal bubble nucleation in graphene nanochannels. J. Phys. Chem. C 2019, 123, 3482-3490. [CrossRef]

29. Sun, K.; Zhao, C.; Zeng, X.; Chen, Y.; Jiang, X.; Ding, X.; Gou, L.; Xie, H.; Li, X.; Zhang, X.; et al. Active DNA unwinding and transport by a membrane-adapted helicase nanopore. Nat. Commun. 2019, 10, 1-11. [CrossRef]

30. Chen, X.; Zhang, Y.; Roozbahani, G.M.; Guan, X. Salt-Mediated nanopore detection of ADAM-17. ACS Appl. Bio Mater. 2019, 2, 504-509. [CrossRef]

31. Wang, L.; Chen, X.; Zhou, S.; Roozbahani, G.M.; Zhang, Y.; Wang, D.; Guan, X. Displacement chemistry-based nanopore analysis of nucleic acids in complicated matrices. Chem. Commun. 2018, 54, 13977-13980. [CrossRef] [PubMed]

32. Verschueren, D.V.; Pud, S.; Shi, X.; De Angelis, L.; Kuipers, L.; Dekker, C. Label-Free optical detection of DNA translocations through plasmonic nanopores. ACS Nano 2019, 13, 61-70. [CrossRef] [PubMed]

33. Feng, J.; Liu, K.; Bulushev, R.D.; Khlybov, S.; Dumcenco, D.; Kis, A.; Radenovic, A. Identification of single nucleotides in MoS2 nanopores. Nat. Nanotechnol. 2015, 10, 1070-1076. [CrossRef] [PubMed]

34. Yusko, E.C.; Bruhn, B.R.; Eggenberger, O.M.; Houghtaling, J.; Rollings, R.; Walsh, N.C.; Nandivada, S.; Pindrus, M.; Hall, A.R.; Sept, D.; et al. Real-time shape approximation and fingerprinting of single proteins using a nanopore. Nat. Nanotechnol. 2017, 12, 360-367. [CrossRef]

35. Zhu, Z.; Duan, X.; Li, Q.; Wu, R.; Wang, Y.; Li, B. Low-Noise nanopore enables in-situ and label-free tracking of a trigger-induced DNA molecular machine at the single-molecular level. J. Am. Chem. Soc. 2020, 142, 4481-4492. [CrossRef]

36. Yuan, B.; Li, S.; Ying, Y.-L.; Long, Y.-T. The analysis of single cysteine molecules with an aerolysin nanopore. Analyst 2020, 145, 1179-1183. [CrossRef]

37. Nazari, M.; Li, X.; Alibakhshi, M.A.; Yang, H.; Souza, K.; Gillespie, C.; Gummuluru, S.; Hong, M.K.; Reinhard, B.M.; Korolev, K.S.; et al. Femtosecond photonic viral inactivation probed using solid-state nanopores. Nano Futur. 2018, 2, 045005. [CrossRef]

38. Lu, Y.; Wu, X.-Y.; Ying, Y.-L.; Long, Y.-T. Simultaneous single-molecule discrimination of cysteine and homocysteine with a protein nanopore. Chem. Commun. 2019, 55, 9311-9314. [CrossRef]

39. Yu, R.J.; Lu, S.M.; Xu, S.W.; Li, Y.J.; Xu, Q.; Ying, Y.L.; Long, Y.T. Single molecule sensing of amyloid-beta aggregation by confined glass nanopores. Chem. Sci. 2019, 10, 10728-10732. [CrossRef]

40. Restrepo-Pérez, L.; Wong, C.H.; Maglia, G.; Dekker, C.; Joo, C. Label-Free detection of post-translational modifications with a nanopore. Nano Lett. 2019, 19, 7957-7964. [CrossRef] 
41. Meng, F.-N.; Ying, Y.-L.; Yang, J.; Long, Y.-T. A wild-type nanopore sensor for protein kinase activity. Anal. Chem. 2019, 91, 9910-9915. [CrossRef] [PubMed]

42. Li, Q.; Ying, Y.-L.; Liu, S.-C.; Lin, Y.; Long, Y.-T. Detection of single proteins with a general nanopore sensor. ACS Sens. 2019, 4, 1185-1189. [CrossRef] [PubMed]

43. Si, W.; Zhang, Y.; Wu, G.; Kan, Y.; Zhang, Y.; Sha, J.; Chen, Y. Discrimination of protein amino acid or its protonated state at single-residue resolution by graphene nanopores. Small 2019, 15, e1900036. [CrossRef] [PubMed]

44. Grinstaff, M.W.; Song, J.; Meller, A.; Grinstaff, M.W. Single-molecule protein sensing in a nanopore: A tutorial. Chem. Soc. Rev. 2018, 47, 8512-8524. [CrossRef]

45. Sha, J.; Si, W.; Xu, B.; Zhang, S.; Li, K.; Lin, K.; Shi, H.; Chen, Y. Identification of spherical and nonspherical proteins by a solid-state nanopore. Anal. Chem. 2018, 90, 13826-13831. [CrossRef] [PubMed]

46. Mayer, M.; Ying, C.; Eggenberger, O.M.; Fennouri, A.; Nandivada, S.; Acharjee, M.; Li, J.; Hall, A.R.; Mayer, M. Estimation of shape, volume, and dipole moment of individual proteins freely transiting a synthetic nanopore. ACS Nano 2019, 13, 5231-5242. [CrossRef]

47. Restrepo-Pérez, L.; Huang, G.; Bohländer, P.R.; Worp, N.; Eelkema, R.; Maglia, G.; Joo, C.; Dekker, C. Correction to resolving chemical modifications to a single amino acid within a peptide using a biological nanopore. ACS Nano 2020, 13, 13668-13676. [CrossRef]

48. Kaur, H.; Nandivada, S.; Acharjee, M.C.; McNabb, D.S.; Li, J.L. Estimating Rna polymerase protein binding sites on lambda DNA using solid-state nanopores. ACS Sens. 2019, 4, 100-109. [CrossRef]

49. Zhou, B.; Wang, Y.-Q.; Cao, C.; Li, D.; Long, Y.-T. Monitoring disulfide bonds making and breaking in biological nanopore at single molecule level. Sci. China Ser. B Chem. 2018, 61, 1385-1388. [CrossRef]

50. Karmi, A.; Sakala, G.P.; Rotem, D.; Reches, M.; Porath, D. Durable, stable, and functional nanopores decorated by self-assembled dipeptides. ACS Appl. Mater. Interfaces 2020, 12, 14563-14568. [CrossRef]

51. Zhao, X.; Ma, R.; Hu, Y.; Chen, X.; Dou, R.; Liu, K.; Cui, C.; Liu, H.; Li, Q.; Pan, D.; et al. Translocation of tetrahedral DNA nanostructures through a solid-state nanopore. Nanoscale 2019, 11, 6263-6269. [CrossRef] [PubMed]

52. Zhu, L.; Xu, Y.; Ali, I.; Liu, L.; Wu, H.; Lu, Z.; Liu, Q. Solid-State nanopore single-molecule sensing of DNAzyme cleavage reaction assisted with nucleic acid nanostructure. ACS Appl. Mater. Interfaces 2018, 10, 26555-26565. [CrossRef] [PubMed]

53. Alibakhshi, M.A.; Halman, J.R.; Wilson, J.; Aksimentiev, A.; Afonin, K.A.; Wanunu, M. Picomolar fingerprinting of nucleic acid nanoparticles using solid-state nanopores. ACS Nano 2017, 11, 9701-9710. [CrossRef] [PubMed]

54. Hiratani, M.; Kawano, R. DNA logic operation with nanopore decoding to recognize MicroRNA patterns in small cell lung cancer. Anal. Chem. 2018, 90, 8531-8537. [CrossRef]

55. Chen, K.; Zhu, J.; Bošković, F.; Keyser, U.F. Nanopore-Based DNA hard drives for rewritable and secure data storage. Nano Lett. 2020, 20, 3754-3760. [CrossRef]

56. Roether, J.; Chu, K.-Y.; Willenbacher, N.; Shen, A.Q.; Bhalla, N. Real-time monitoring of DNA immobilization and detection of DNA polymerase activity by a microfluidic nanoplasmonic platform. Biosens. Bioelectron. 2019, 142, 111528. [CrossRef]

57. Kim, D.M.; Yoo, S.M. DNA-modifying enzyme reaction-based biosensors for disease diagnostics: Recent biotechnological advances and future perspectives. Crit. Rev. Biotechnol. 2020, 40, 787-803. [CrossRef]

58. Lei, S.; Liu, Z.; Xu, L.L.; Zou, L.N.; Li, G.P.; Ye, B.X. A “signal-on” electrochemical biosensor based on dnazyme-driven bipedal DNA walkers and Tdt-mediated cascade signal amplification strategy. Anal. Chim. Acta 2020, 1100, 40-46. [CrossRef]

59. Feng, Q.-M.; Zhou, Z.; Li, M.-X.; Zhao, W.; Xu, J.-J.; Chen, H.-Y. DNA tetrahedral scaffolds-based platform for the construction of electrochemiluminescence biosensor. Biosens. Bioelectron. 2017, 90, 251-257. [CrossRef]

60. Zhou, G.; Lin, M.; Song, P.; Chen, X.; Chao, J.; Wang, L.; Huang, Q.; Huang, W.; Fan, C.; Zuo, X. Multivalent capture and detection of cancer cells with DNA nanostructured biosensors and multibranched hybridization chain reaction amplification. Anal. Chem. 2014, 86, 7843-7848. [CrossRef]

61. Ge, Z.-L.; Lin, M.; Wang, P.; Pei, H.; Yan, J.; Shi, J.; Huang, Q.; He, D.; Fan, C.; Zuo, X. Hybridization chain reaction amplification of MicroRNA detection with a tetrahedral DNA nanostructure-based electrochemical biosensor. Anal. Chem. 2014, 86, 2124-2130. [CrossRef] [PubMed]

62. Li, J.; Li, F.; Pei, H.; Wang, L.; Huang, Q.; Fan, C. Construction of functional DNA nanostructures for theranostic applications. Adv. Theranostic Mater. 2014, 47, 550-559. [CrossRef]

63. Pei, H.; Lu, N.; Wen, Y.; Song, S.; Liu, Y.; Yan, H.; Fan, C. A DNA nanostructure-based biomolecular probe carrier platform for electrochemical biosensing. Adv. Mater. 2010, 22, 4754-4758. [CrossRef] [PubMed]

64. Lin, M.H.; Wang, J.J.; Zhou, G.B.; Wang, J.B.; Wu, N.; Lu, J.X.; Gao, J.M.; Chen, X.Q.; Shi, J.Y.; Zuo, X.L.; et al. Programmable engineering of a biosensing interface with tetrahedral DNA nanostructures for ultrasensitive DNA detection. Angewandte Chemie-Int. Ed. 2015, 54, 2151-2155. [CrossRef] [PubMed]

65. Pei, H.; Liang, L.; Yao, G.B.; Li, J.; Huang, Q.; Fan, C.H. Reconfigurable three-dimensional DNA nanostructures for the construction of intracellular logic sensors. Angewandte Chemie-Int. Ed. 2012, 51, 9020-9024.

66. Chen, Q.; Liu, H.; Lee, W.; Sun, Y.; Zhu, D.; Pei, H.; Fan, C.; Fan, X. Self-assembled DNA tetrahedral optofluidic lasers with precise and tunable gain control. Lab. A Chip 2013, 13, 3351-3354. [CrossRef]

67. Kwok, H.; Briggs, K.; Tabard-Cossa, V. Nanopore fabrication by controlled dielectric breakdown. PLoS ONE 2014, 9, e92880. [CrossRef] 